PAPER

CrossMark

\title{
Investigation of angstrom-thick aluminium oxide passivation layers to improve the gate lag performance of GaN HEMTs
}

PEVISED

21 June 2019

ACCEPTED FOR PUBLICATION

4 July 2019

PUBLISHED

12 July 2019

\author{
Melisa Ekin Gulseren ${ }^{1,2} \oplus$, Gokhan Kurt $^{2} \oplus$, Turkan Gamze Ulusoy Ghobadi ${ }^{3,4}$, Amir Ghobadi ${ }^{1,2}$, \\ Gurur Salkim ${ }^{2}$, Mustafa Ozturk ${ }^{2}$, Bayram Butun ${ }^{2}$ (1) and Ekmel Ozbay ${ }^{1,2,3,5}$ \\ 1 Department of Electrical and Electronics Engineering, Bilkent University, 06800 Ankara, Turkey \\ 2 Nanotechnology Research Center, Bilkent University, 06800 Ankara, Turkey \\ 3 UNAM-Institute of Materials Science and Nanotechnology, Bilkent University, 06800 Ankara, Turkey \\ 4 Department of Energy Engineering, Faculty of Engineering, Ankara University, 06830 Ankara, Turkey \\ 5 Department of Physics, Bilkent University, 06800 Ankara, Turkey \\ E-mail:melisa.gulseren@bilkent.edu.tr
}

Keywords: AlGaN, atomic layer deposition, dielectric, GaN, gate lag, HEMT, passivation

\begin{abstract}
In this paper, we report an angstrom-thick atomic layer deposited (ALD) aluminum oxide $\left(\mathrm{Al}_{2} \mathrm{O}_{3}\right)$ dielectric passivation layer for an $\mathrm{AlGaN} / \mathrm{GaN}$ high electron mobility transistor (HEMT). Our results show a 55\% improvement in the gate lag performance of the design and a decrease by half in interface state density upon coating with two cycles of $\mathrm{ALD} \mathrm{Al}_{2} \mathrm{O}_{3}$. DC characteristics such as current density, threshold voltage, and leakage currents were maintained. $\mathrm{ALD} \mathrm{Al}_{2} \mathrm{O}_{3}$ passivation layers with thicknesses up to $10 \mathrm{~nm}$ were investigated. XPS analyses reveal that the first ALD cycles are sufficient to passivate $\mathrm{GaN}$ surface traps. This study demonstrates that efficient passivation can be achieved in atomic-scale with dimensions much thinner than commonly used bulk layers.
\end{abstract}

\section{Introduction}

GAN based high electron mobility transistors (HEMTs) are advantageous for high power and high frequency applications due to their superior properties such as wide band gap, high breakdown field, and high saturation velocity [1-3]. Although GaN HEMTs are widely preferred for a variety of commercial and military applications, unpassivated devices suffer from limitations in characteristics such as radio frequency (RF) current, transconductance, and breakdown voltage as a result of the trapping of electrons in the surface states created by defects and dislocations [4,5]. Surface passivation has become the most established approach to address the problem of current collapse, due to its simplicity and efficacy, with $\mathrm{SiN}_{\mathrm{x}}$ being the most commonly preferred dielectric [6-8]. $\mathrm{SiN}_{\mathrm{x}}$ passivation schemes are particularly effective for III-N devices due to the relatively low state density at the $\mathrm{SiN}_{\mathrm{x}} / \mathrm{III}-\mathrm{N}$ interface and the possibility of in situ MOCVD deposition [9]. Numerous other dielectrics have been demonstrated as passivation layers over the years with different advantages [10-12]. $\mathrm{Al}_{2} \mathrm{O}_{3}$ passivation has been demonstrated with record drain current and transconductance and improved pulsed I- $\mathrm{V}$ characteristics [13-15]. $\mathrm{Al}_{2} \mathrm{O}_{3}$ is an attractive material because of its large bandgap, relatively high dielectric constant, and high breakdown field and has the advantage of high quality oxide/III-N interfaces when atomic layer deposited (ALD) [16].

Recently, angstrom-thick passivation has been demonstrated as an efficient route to provide both surface coverage and trap passivation in various applications [17-20]. It was found that the first ALD cycles will only passivate surface defects without introducing any new bulk traps. Thus, it is envisioned that this atomic-scale selective passivation is the optimal way for GaN HEMTs.

In this paper, we demonstrate that two $\mathrm{ALD}$ cycles of $\mathrm{Al}_{2} \mathrm{O}_{3}$ will lead to about $55 \%$ improvement in the gate lag characteristic of the GaN HEMT compared to that of an unpassivated design. This improvement has been correlated with the reduction in the density of GaN surface traps, which has been studied with frequency dependent conductance measurements. An in-depth XPS surface analysis confirmed that $2 \mathrm{~A} \mathrm{Al}_{2} \mathrm{O}_{3}$ is sufficient 


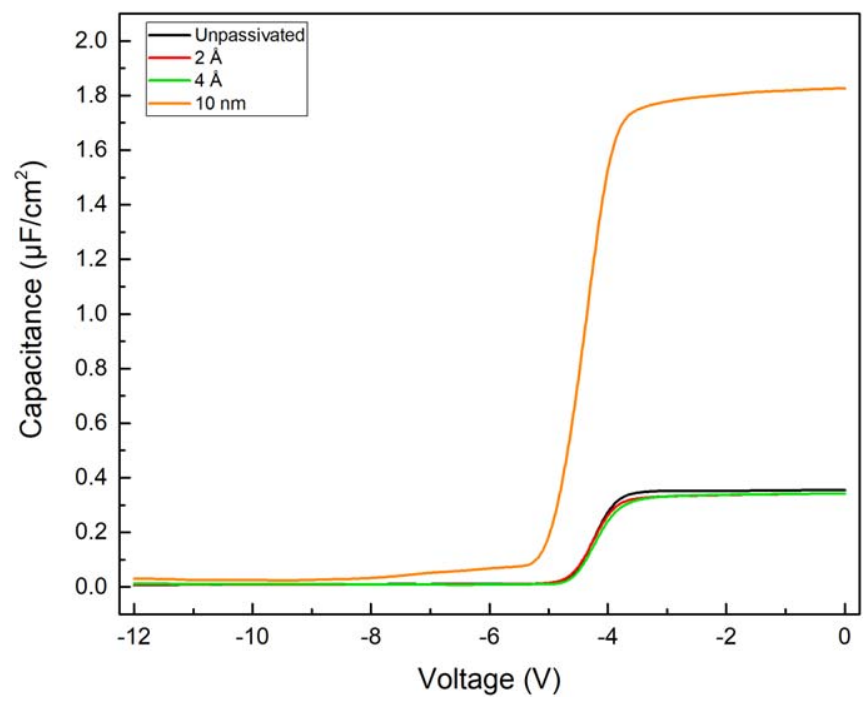

Figure 1. C-V characteristics at 1-MHz frequency for unpassivated, $2 \AA, 4 \AA$, and $10 \mathrm{~nm} \mathrm{ALD} \mathrm{Al}_{2} \mathrm{O}_{3}$ passivated AlGaN/GaN HEMTs.

for passivation of the $\mathrm{AlGaN}$ surface. DC characteristics such as knee voltage and transconductance were improved and other characteristics were maintained for the passivated device.

\section{Device fabrication}

The epitaxial structure consists of a $20 \mathrm{~nm}$ AlN nucleation layer and $1350 \mathrm{~nm}$ Carbon doped high resistive buffer layer on a semi-insulating SiC wafer, followed by $150 \mathrm{~nm}$ high mobility GaN channel, $1 \mathrm{~nm}$ AlN spacer, and $22 \mathrm{~nm}$ AlGaN barrier layer with 26\% Aluminum content capped with $3 \mathrm{~nm} \mathrm{GaN}$. The electron mobility and 2DEG density were found to be $2061 \mathrm{~cm}^{2} \mathrm{~V}^{-1}$.s and $1.07 \times 10^{13} \mathrm{~cm}^{-2}$ respectively. Average sheet resistivity was $284 \mathrm{Ohms} / \mathrm{Sq}$ across the 3 inch wafer. Device fabrication began with mesa isolation. Ohmic contacts were formed with electron beam deposited $\mathrm{Ti} / \mathrm{Al} / \mathrm{Ni} / \mathrm{Au}$ stack, followed by $30 \mathrm{~s}$ rapid thermal annealing at $850{ }^{\circ} \mathrm{C}$ in $\mathrm{N}_{2}$ ambient. $250 \mathrm{~nm}$ gate contacts were formed with electron beam lithography and $\mathrm{Ni} / \mathrm{Au}$ gate metal deposition. For device passivation $\mathrm{Al}_{2} \mathrm{O}_{3}$ depositions were carried out at $200^{\circ} \mathrm{C}$ in an ALD reactor (Cambridge Nanotech Savannah S100) employing $\mathrm{Al}\left(\mathrm{CH}_{3}\right)_{3}$ solution as the deposition precursor. The pulse and purge durations were 0.015 and $10 \mathrm{~s}$, respectively. Water was used as the oxygen precursor. The deposition rate was found as $1 \AA /$ cycle. Different devices were fabricated with 2 cycles, 4 cycles, 10 cycles, and 100 cycles to obtain passivation layer thicknesses of $2 \AA, 4 \AA, 1 \mathrm{~nm}$, and $10 \mathrm{~nm}$, respectively. The devices in this letter have a gate width of $2 \times 125 \mu \mathrm{m}$, a gate-source spacing of $1.5 \mu \mathrm{m}$, and gate drain spacing of $3.25 \mu \mathrm{m}$. Schottky diodes were fabricated with a similar process flow for capacitance measurements.

\section{Results and discussion}

Capacitance-voltage $(\mathrm{C}-\mathrm{V})$ measurements of fabricated Schottky diodes were conducted in order to examine the gate characteristics of the different passivation schemes. Figure 1 shows the $\mathrm{C}-\mathrm{V}$ characteristics for the unpassivated, $2 \AA, 4 \AA$, and $10 \mathrm{~nm} \mathrm{ALD} \mathrm{Al}_{2} \mathrm{O}_{3}$ passivated samples measured at a frequency of $1 \mathrm{MHz}$. For the unpassivated, $2 \AA$, and $4 \AA$ passivated samples similar capacitance curves are obtained. An increase in capacitance is observed for the $10 \mathrm{~nm} \mathrm{Al}_{2} \mathrm{O}_{3}$ passivated sample, confirming the formation of the oxide layer. A negative threshold shift is also observed for the sample with $10 \mathrm{~nm}$ passivation.

Frequency dependent conductance measurements were carried out to determine the interface state density $D_{i t}$. The frequency was varied from $10 \mathrm{kHz}$ to $2 \mathrm{MHz}$. The parallel $C_{m}-G_{m}$ circuit was considered for the equivalent circuit to the interface. The interface state density was obtained from [21] as

$$
\frac{G_{P}}{\omega}=\frac{q \omega \tau_{i t} D_{i t}}{1+\left(\omega \tau_{i t}\right)^{2}}=\frac{\omega G_{m} C_{o x}^{2}}{G_{m}^{2}+\omega^{2}\left(C_{o x}-C_{m}\right)^{2}}
$$

where $C_{m}$ and $G_{m}$ are the measured capacitance and conductance at frequency $\omega$, and $C_{o x}$ is the oxide capacitance. The calculated $G_{p} / \omega$ values for the unpassivated, $2 \AA, 4 \AA$, and $10 \mathrm{~nm} \mathrm{ALD} \mathrm{Al}_{2} \mathrm{O}_{3}$ passivated schemes are shown in Figure 2. The extracted $D_{i t}$ values are given in Table 1. The relative position of the trap energy level 


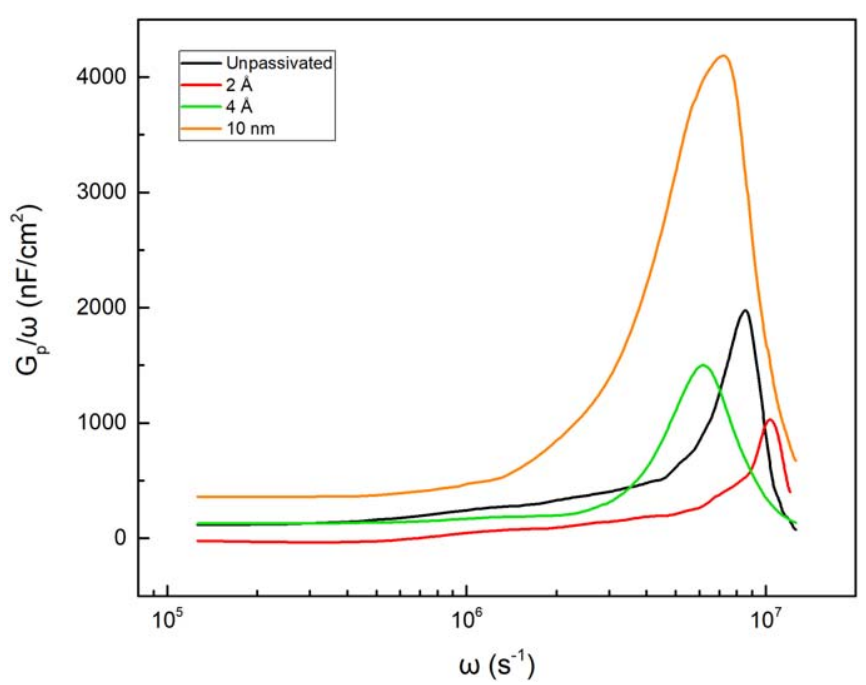

Figure 2. Calculated values of trap conductance as a function of angular frequency for unpassivated, $2 \AA, 4 \AA$, and $10 \mathrm{~nm} \mathrm{ALD} \mathrm{Al}_{2} \mathrm{O}_{3}$ passivated AlGaN/GaN HEMTs.

Table 1. List of measurements for devices with no passivation, $2 \AA, 4 \AA, 1 \mathrm{~nm}$, and $10 \mathrm{~nm} \mathrm{ALD} \mathrm{grown} \mathrm{Al}_{2} \mathrm{O}_{3}$.

\begin{tabular}{|c|c|c|c|c|c|c|}
\hline Parameter & Units & Unpassivated & $2 \AA$ & $4 \AA$ & $1 \mathrm{~nm}$ & $10 \mathrm{~nm}$ \\
\hline$D_{i t}$ & $\mathrm{eV}^{-1} \mathrm{~cm}^{-2}$ & $3.08 \times 10^{13}$ & $1.62 \times 10^{13}$ & $2.36 \times 10^{13}$ & - & $6.52 \times 10^{13}$ \\
\hline $\mathrm{I}_{\mathrm{dss}}$ & $\mathrm{A} \mathrm{mm}^{-1}$ & 0.75 & 0.78 & 0.79 & 0.79 & 0.82 \\
\hline$V_{\text {knee }}$ & $\mathrm{V}$ & 8.6 & 8 & 6.8 & 6.8 & 6.5 \\
\hline $\mathrm{V}_{\text {th }}$ & $\mathrm{V}$ & -4.06 & -4.07 & -4.07 & -4.07 & -4.15 \\
\hline $\mathrm{g}_{\mathrm{m}}$ & $\mathrm{mS} \mathrm{mm} \mathrm{m}^{-1}$ & 179 & 186 & 187 & 188 & 188 \\
\hline $\mathrm{I}_{\mathrm{g} \text {,leak }}$ & $\mathrm{nA} \mathrm{mm} \mathrm{m}^{-1}$ & 2.7 & 3.4 & 1.9 & 1.6 & 21.4 \\
\hline $\mathrm{I}_{\text {d.leak }}$ & $\mathrm{nA} \mathrm{mm} \mathrm{m}^{-1}$ & 8.3 & 12.7 & 19.3 & 20.3 & 206 \\
\hline Gate Lag & $\%$ & 20.3 & 9.4 & 11.0 & 11.8 & 8.5 \\
\hline
\end{tabular}

with respect to the conduction band edge is found to be in the range of $0.18-0.19 \mathrm{eV}$ and the time constants in the range of $0.19-0.32 \mu \mathrm{s}$ for the samples. An interface state density of $3.08 \times 10^{13} \mathrm{eV}^{-1} \mathrm{~cm}^{-2}$ is obtained for the unpassivated sample. For the $2 \AA \mathrm{Al}_{2} \mathrm{O}_{3}$ sample the lowest $D_{i t}$ of the studied samples is obtained, with a value of $1.62 \times 10^{13} \mathrm{eV}^{-1} \mathrm{~cm}^{-2}$, which corresponds to nearly a $50 \%$ decrease in $D_{i t}$ compared to the unpassivated sample. For the $4 \AA_{\mathrm{Al}_{2} \mathrm{O}_{3}}$ sample a slight increase is observed in the interface state density, however the obtained value of $2.36 \times 10^{13} \mathrm{eV}^{-1} \mathrm{~cm}^{-2}$ is still lower than that achieved for the unpassivated sample. For the $10 \mathrm{~nm} \mathrm{Al}_{2} \mathrm{O}_{3}$ sample, however, the highest $D_{i t}$ of $6.52 \times 10^{13} \mathrm{eV}^{-1} \mathrm{~cm}^{-2}$ is calculated, which corresponds to a nearly $50 \%$ increase compared to the unpassivated sample. Thus, the conductance method measurements indicate that angstrom thick ALD passivation layers are able to passivate surface states selectively whereas thicker layers lead to increased surface state density.

Table 1 lists the DC measurement results and calculated gate lag percentages for different devices, that are, unpassivated, $2 \AA, 4 \AA, 1 \mathrm{~nm}$, and $10 \mathrm{~nm}$ ALD deposited $\mathrm{Al}_{2} \mathrm{O}_{3}$. Figure 3 compares the transfer characteristics and gate currents of the devices for each passivation scheme, at $V_{D}=10 \mathrm{~V}$. The threshold voltage was obtained as $-4.06 \mathrm{~V}$ for the unpassivated device using linear extrapolation at maximum linear slope and does not vary significantly for $2 \AA, 4 \AA$, and $1 \mathrm{~nm} \mathrm{Al}_{2} \mathrm{O}_{3}$ passivation. For $10 \mathrm{~nm} \mathrm{ALD} \mathrm{Al}_{2} \mathrm{O}_{3}$ passivation, $\mathrm{V}_{\text {th }}$ decreases to $-4.15 \mathrm{~V}$, analogous to the decrease observed in the $\mathrm{C}-\mathrm{V}$ measurement, due to the increased sheet charge from the passivation layer. The measured output characteristics are shown in Figure 4 . The drain current density $\mathrm{I}_{\mathrm{dss}}$ (at a gate voltage of $\mathrm{V}_{\mathrm{G}}=1 \mathrm{~V}$ ) was obtained as $0.75 \mathrm{~A} \mathrm{~mm}^{-1}$ for the unpassivated reference device, which increased slightly by $5 \%$ to a value of $0.79 \mathrm{~A} \mathrm{~mm}^{-1}$ for the $4 \AA$ and $1 \mathrm{~nm}$ passivation scheme and by $10 \%$ to a maximum value of $0.82 \mathrm{~A} \mathrm{~mm}^{-1}$ for the $10 \mathrm{~nm}$ passivation scheme. Similarly, the peak transconductance value increased by $4.7 \%$ from $179 \mathrm{mS} \mathrm{mm}^{-1}$ for the reference device to $188 \mathrm{mS} \mathrm{mm}^{-1}$ for the devices with $1 \mathrm{~nm}$ and $10 \mathrm{~nm}$ passivation. An improvement in knee voltage is observed with increasing $\mathrm{Al}_{2} \mathrm{O}_{3}$ passivation thickness. The reason for these improvements in the drain current characteristics is related to enhanced electron transport caused by an increase in sheet carrier concentration, due to the reduction in surface states.

The drain leakage current $\mathrm{I}_{\mathrm{d} \text {,leak }}$ is extracted from the transfer characteristics measurements as the current at $\mathrm{V}_{\mathrm{G}}=-6 \mathrm{~V}$ and $\mathrm{V}_{\mathrm{D}}=10 \mathrm{~V}$. $\mathrm{I}_{\mathrm{d} \text {,leak }}$ increases monotonically with passivation layer thickness, which is also 


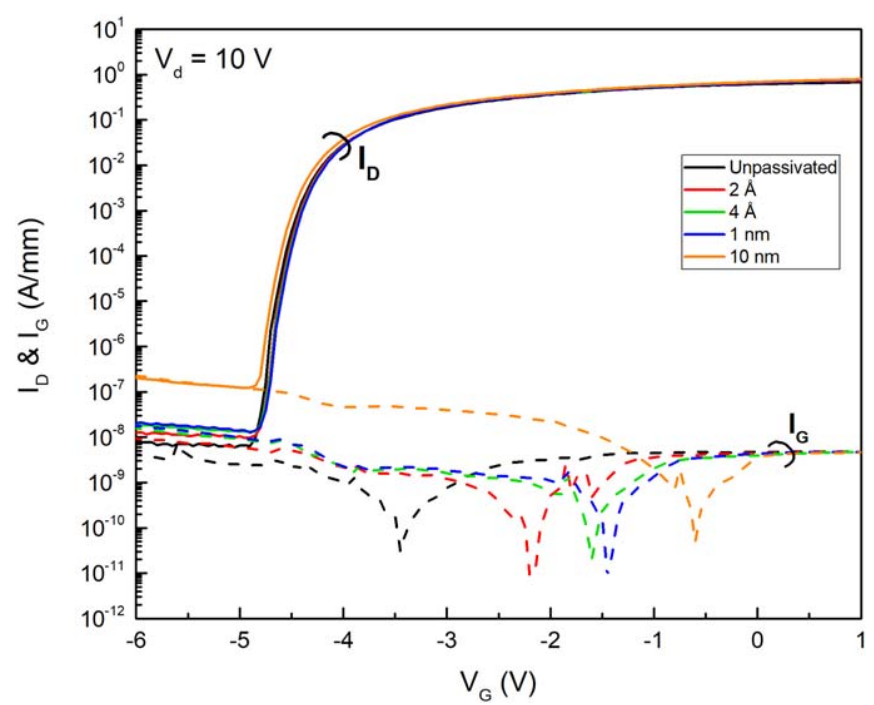

Figure 3. Transfer characteristics and gate leakage for unpassivated, $2 \AA, 4 \AA, 1 \mathrm{~nm}$, and $10 \mathrm{~nm} \mathrm{ALD} \mathrm{Al}{ }_{2} \mathrm{O}_{3}$ passivated $\mathrm{AlGaN} / \mathrm{GaN}$ HEMTs.

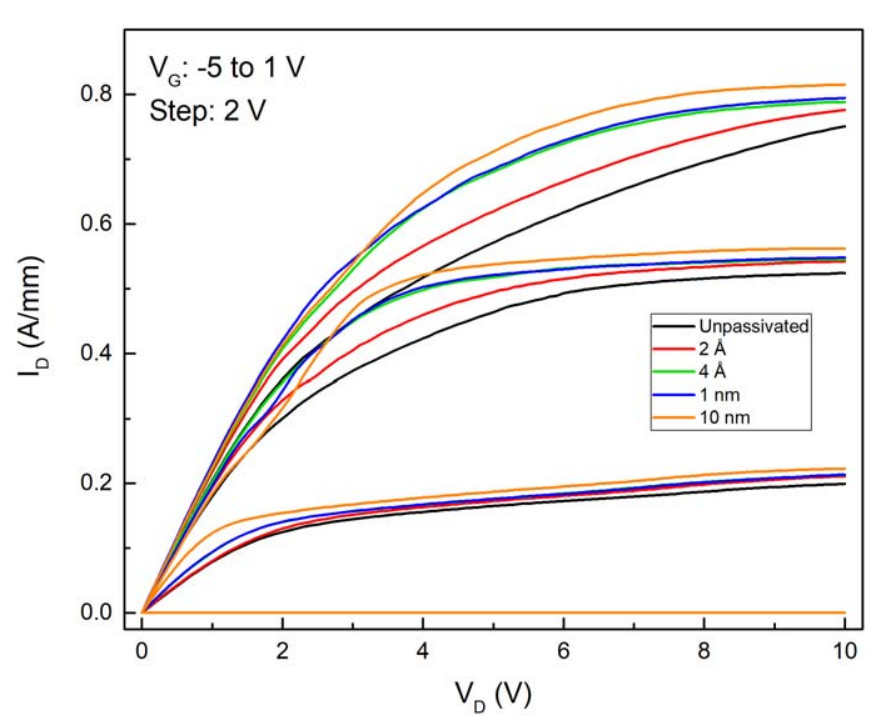

Figure 4. Output characteristics for unpassivated, $2 \AA, 4 \AA, 1 \mathrm{~nm}$, and $10 \mathrm{~nm} \mathrm{ALD} \mathrm{Al}_{2} \mathrm{O}_{3}$ passivated AlGaN/GaN HEMTs.

attributed to the increasing sheet charge of the 2DEG. The Schottky characteristics of the AlGaN/GaN HEMTs were measured with a floating drain contact (Figure 5) and the gate leakage current $I_{\mathrm{g}, \text { leak }}$ is obtained from this measurement as the gate current at $\mathrm{V}_{\mathrm{G}}=-6 \mathrm{~V}$. The reverse gate leakage current, in contrast to the drain leakage current, does not follow a monotonically increasing trend, indicating that the reverse gate leakage current is not dominated by surface leakage. The reverse gate leakage current increases for the initial passivation $2 \AA$, decreases for the two subsequent passivation thicknesses, then increases to its highest value for the greatest passivation thickness of $10 \mathrm{~nm}$. The dominant mechanism of gate leakage is attributed to be edge gate leakage current, as the trend of the reverse gate leakage current for increasing passivation thickness correlates inversely with the trend in the gate lag characteristic. A decrease in gate lag corresponds to an increase in gate leakage, indicating that extension of the gate depletion region towards the drain by the virtual gate effect acting to disperse the electric field lines induced by the depletion region reduces the edge current [22]. Passivation that suppresses the virtual gate thereby leads to an increase in gate leakage current. Low forward gate leakage current and nearly constant gate turn on voltage is maintained for each passivation scheme.

To further understand the correlation between the passivation layer and the surface states gate lag measurements were carried out. The gate lag measurements were performed using an Agilent E3631A power supply, Keysight Technologies 33500B waveform generator, and a Keysight InfiniVision DSOX2004A 


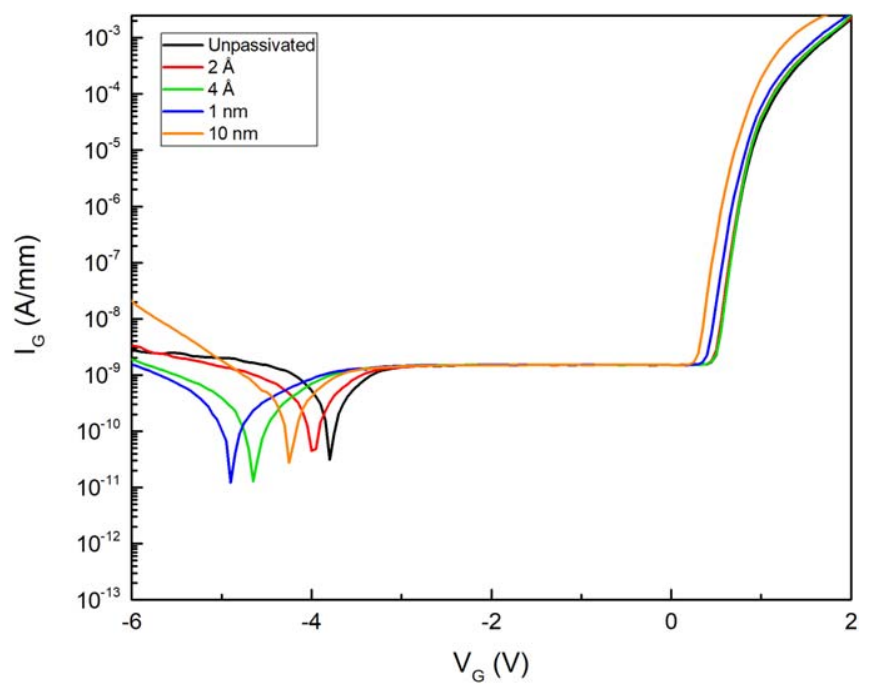

Figure 5. $\mathrm{I}_{\mathrm{G}}-\mathrm{V}_{\mathrm{GS}}$ characteristics measured with floating drain contact for unpassivated, $2 \AA, 4 \AA, 1 \mathrm{~nm}$, and $10 \mathrm{~nm} \mathrm{ALD} \mathrm{Al}_{2} \mathrm{O}_{3}$ passivated AlGaN/GaN. HEMTs.

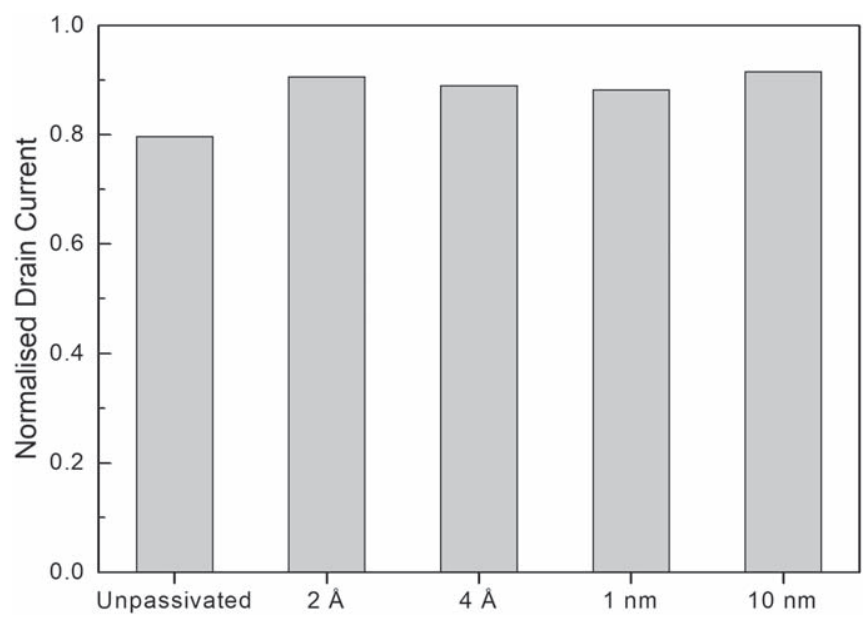

Figure 6. Drain current response of the pulsed gate voltage normalized to DC values with $\mathrm{V}_{\mathrm{D}}=0 \mathrm{~V}$ and $\mathrm{V}_{\mathrm{G}}$ pulsed from $-6 \mathrm{~V}$ to $0 \mathrm{~V}$ for unpassivated, $2 \AA, 4 \AA, 1 \mathrm{~nm}$, and $10 \mathrm{~nm} \mathrm{ALD} \mathrm{Al}{ }_{2} \mathrm{O}_{3}$ passivated AlGaN/GaN HEMTs. The pulsewidth is $1 \mu$ s at $5 \%$ duty cycle.

oscilloscope. The measurements were carried out by pulsing the gate from $-6 \mathrm{~V}$ to $0 \mathrm{~V}$, with a pulse width of $1 \mu \mathrm{s}$ and period of $20 \mu$ s with the drain kept at $0 \mathrm{~V}$. The pulsed drain current response with respect to the DC values are compared in Figure 6 for the studied passivation schemes. A gate lag of $20.9 \%$ is obtained for the unpassivated device, which improves by $55 \%$ to a gate lag value of $9.5 \%$ for the device with $2 \AA$ passivation. For the $4 \AA$ and $1 \mathrm{~nm} \mathrm{Al}_{2} \mathrm{O}_{3}$ passivation layers, a slight increase in the gate lag characteristics is observed, however, significant improvement compared to the unpassivated case is maintained. For $10 \mathrm{~nm} \mathrm{Al}_{2} \mathrm{O}_{3}$ passivation layer the lowest gate lag of $8.7 \%$ is observed. [23] reports that for $\mathrm{ALD} \mathrm{Al}_{2} \mathrm{O}_{3}$ passivation thicknesses between $10 \mathrm{~nm}$ and $40 \mathrm{~nm}$, increasing passivation thickness leads to decreasing current collapse, enabling the reduction of the current collapse below $15 \%$. The results of this study indicate the same trend if passivation layers greater than $10 \mathrm{~nm}$ were studied, however, it is demonstrated that similar reduction in current collapse can be achieved with passivation layers as thin as $2 \AA$.

To gain insight on the passivation property of $\mathrm{ALD} \mathrm{Al}_{2} \mathrm{O}_{3}$ layer, $\mathrm{x}$-ray photoelectron spectroscopy (XPS) is utilized for unpassivated and $2 \mathrm{~A} \mathrm{Al}_{2} \mathrm{O}_{3}$ coated samples. Before ALD process, all the samples have been treated with a diluted $\mathrm{HCl}$ acid to remove the natural oxide layer. Figure 7 shows the N1s and Ga3d spectra of these two samples. Peak position correction was calibrated by referencing the $\mathrm{C} 1 \mathrm{~s}$ orbital peak position $(284.8 \mathrm{eV})$ and the other peaks in the spectrum were shifted accordingly. As previously explained in several reports, the dominant surface defects of $\mathrm{GaN}$ are $\mathrm{Ga}$ and $\mathrm{N}$ vacancies (or dangling bonds). Based on the calculation of free energy by classical nucleation theory, most of the oxygen-derived hydroxyl groups such as $\mathrm{OH}$ radicals and $\mathrm{H}_{2} \mathrm{O}$ or $\mathrm{O}_{2}$ will 


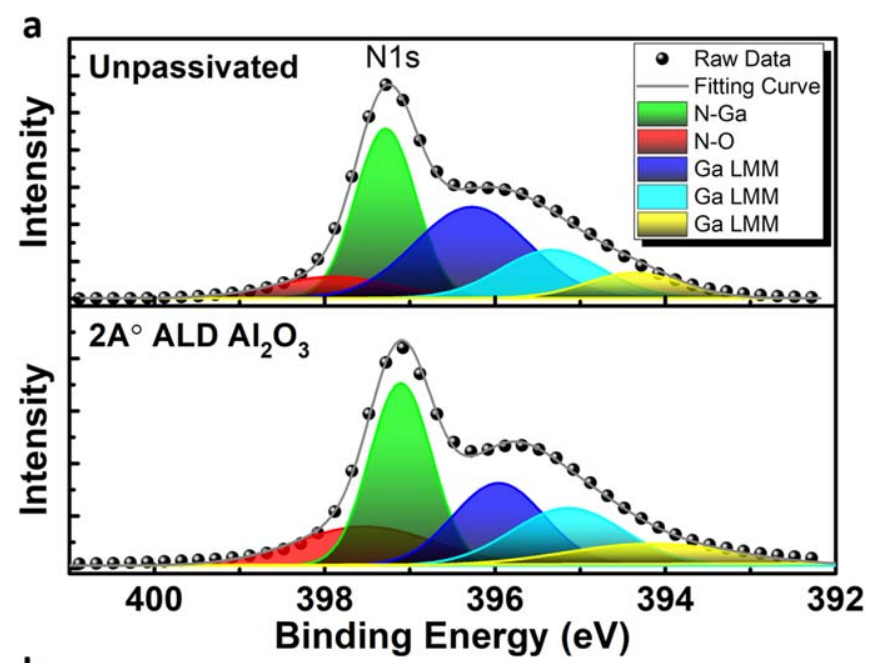

b

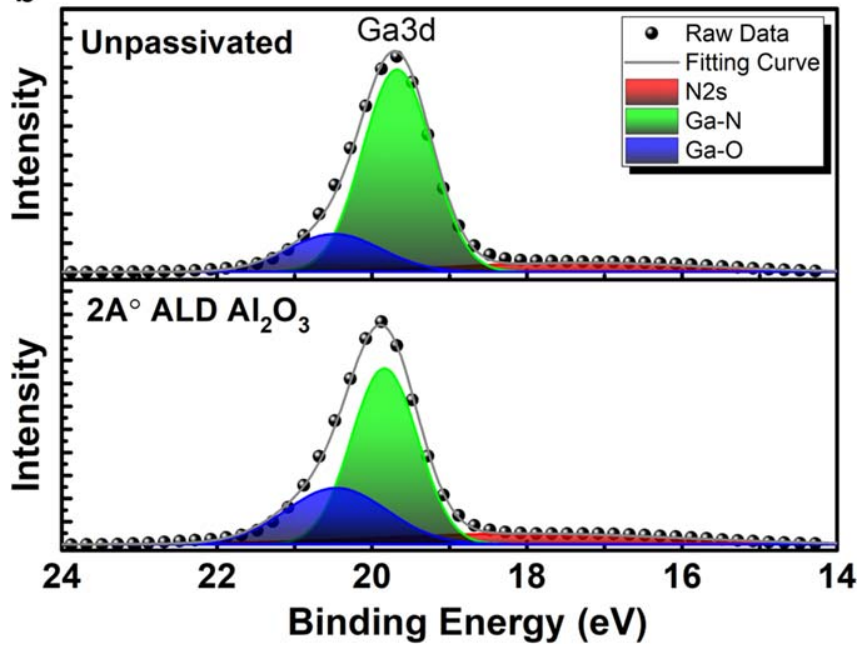

Figure 7. (a) N1s and (b) Ga3d high resolution XPS pattern of the resulting unpassivated and $2 \AA$ thick $\mathrm{Al}_{2} \mathrm{O}_{3}$ coated samples, respectively.

be chemisorbed near imperfections such as dangling bonds and vacancies. Looking back into Figure 7(a), the N1s spectra is deconvoluted into five main peaks [24]; three of which are assigned into Auger Ga LMM peaks, the dominant one comes from the Ga-N bond, and the one in the higher energy tail is attributed to N-O bonds. As we can see, the passivated sample has a stronger N-O related peak. During the ALD process, the Ga vacancy positions are passivated by oxygen molecules and form these $\mathrm{N}-\mathrm{O}$ bonds. On the other side, the Ga3d spectra can be scrutinized to gain a further insight on the surface properties of the GaN layer. As illustrated in Figure 7(b), this spectrum is deconvoluted into three Gaussian profiles [25]; a broad and weak response originated from N2s orbitals, a dominant peak assigned to Ga-N bond, and a high energy response from $\mathrm{Ga}-\mathrm{O}$ bonds. Looking at these peaks, it can be clearly seen that the $\mathrm{Ga}-\mathrm{O}$ related peak is more dominant for $2 \AA \mathrm{Al}_{2} \mathrm{O}_{3}$ passivated case (compared to the unpassivated one). Therefore, similar to $\mathrm{N} 1 \mathrm{~s}$ data, the $\mathrm{Al}_{2} \mathrm{O}_{3}$ passivation layer will substitute $\mathrm{N}$ vacant positions and facilitate formation of $\mathrm{Ga}-\mathrm{O}$ bonds. All the above-mentioned results confirm the efficient passivation of surface traps upon coating with the $2 \mathrm{AAl}_{2} \mathrm{O}_{3}$ layer. Oxygen-containing gas molecules tend to be chemisorbed on the surface of a semiconductor host through the capture of free electrons. Consequently, these chemisorbed radicals reduce the density of free carriers in the vicinity of the semiconductor surface and deplete the surface electron states. This, in turn, triggers the existence of the space charge region and induces band bending near the interface. On the other hand, these chemisorbed oxygen molecules are likely attached into trap states and dangling bonds. The passivation of surface traps, in first ALD cycles, reduces the surface traps density, mitigates adsorption of oxygen radicals, and consequently reduces band bending. However, as we go to larger ALD cycles, bulk trap states in $\mathrm{Al}_{2} \mathrm{O}_{3}$ layer start to become dominant and therefore diminish the abovementioned characteristics. Moreover, the Al2p spectra have been extracted for $2 \AA$ and $10 \mathrm{~nm}$ coated samples. As Figure 8 clearly illustrates, the portion related to $\mathrm{Al}$ element is the major peak for the thin passivated sample. However, as we increase the $\mathrm{Al}_{2} \mathrm{O}_{3}$ layer thickness to $10 \mathrm{~nm}$, the spectrum is mainly attributed to the 


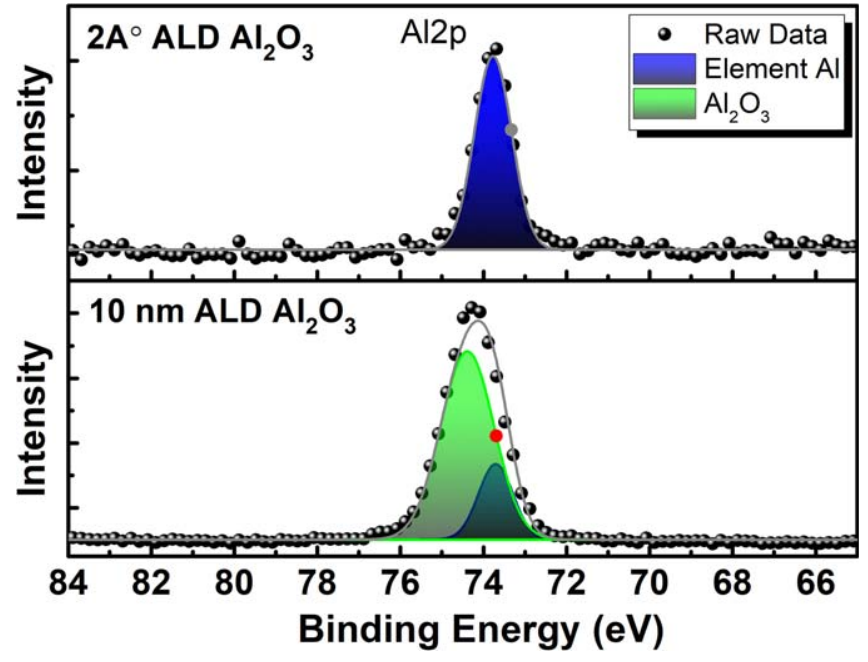

Figure 8. Al2p high resolution XPS pattern of the resulting $2 \AA$ thick and $10 \mathrm{~nm} \mathrm{Al} \mathrm{O}_{3}$ coated samples.

oxide related peak. Thus, the first two ALD cycle just passivates the defect states and does not form a continuous $\mathrm{Al}_{2} \mathrm{O}_{3}$ layer. However, the subsequent cycles trigger the formation of a continuous layer.

\section{Conclusion}

In conclusion, an angstrom-thick $\mathrm{ALD} \mathrm{Al}_{2} \mathrm{O}_{3}$ dielectric is reported for the passivation of surface traps in $\mathrm{AlGaN} /$ GaN HEMTs and passivation thicknesses up to $10 \mathrm{~nm}$ are studied. For the a passivation layer as thin as $2 \AA$ $\mathrm{Al}_{2} \mathrm{O}_{3}$, a greater than $50 \%$ improvement in gate lag compared to the unpassivated device is achieved. Improvements in DC characteristics such as drain current density, knee voltage, and transconductance are observed. XPS analysis confirms that Ga vacancy positions are are passivated by oxygen molecules for $\mathrm{Al}_{2} \mathrm{O}_{3}$ as thin as $2 \AA$.

\section{Acknowledgments}

This work is supported by the TUBITAK under Project No. 116F041. One of the authors (E.O.) also acknowledges partial support from the Turkish Academy of Sciences.

\section{ORCID iDs}

Melisa Ekin Gulseren (iD https://orcid.org/0000-0002-9375-2337

Gokhan Kurt (i) https://orcid.org/0000-0002-1210-4013

Bayram Butun (1D) https://orcid.org/0000-0003-0892-4681

\section{References}

[1] Mishra U K, Parikh P and Wu Y-F AlGaN/GaN HEMTs-an overview of device operation and applications Proc. IEEE 90 1022-31

[2] Chen K Jet al GaN-on-Si power technology: devices and applications IEEE Trans. Electron Devices 64 779-95

[3] Chung J W, Hoke W E, Chumbes E M and Palacios T AlGaN/GaN HEMT with 300-GHz f $\mathrm{m}_{\max }$ IEEE Electron Device Lett. 31 195-7

[4] Lu W, Kumar V, Schwindt R, Piner E and Adesida I 2002 A comparative study of surface passivation on AlGaN/GaN HEMTs SolidState Electronics 46 1441-4

[5] Vertiatchikh A V and Eastman L F 2003 Effect of the surface and barrier defects on the AlGaN/GaN HEMT low-frequency noise performance IEEE Electron Device Lett. 24 535-7

[6] Edwards A P, Mittereder J A, Binari S C, Katzer D S, Storm D F and Roussos J A 2005 Improved reliability of AlGaN-GaN HEMTs using an $\mathrm{NH}_{3}$ plasma treatment prior to SiN passivation IEEE Electron Device Lett. 26 225-7

[7] Lee J-S, Vescan A, Wieszt A, Dietrich R, Leier H and Kwon Y-S Small signal and power measurements of AlGaN/GaN HEMT with SiN passivation Electron. Lett 37 130-2

[8] Green B M, Chu K K, Chumbes E M, Smart J A, Shealy J R and Eastman L F The effect of surface passivation on the microwave characteristics of undoped AlGaN/GaN HEMTs IEEE Electron Device Lett. 21 268-70

[9] Yatabe Z, Asubar J T and Hashizume T 2016 Insulated gate and surface passivation structures for GaN-based power transistors J. Phys. D: Appl. Phys. 49393001 
[10] Liu C, Chor E F and Tan L S 2007 Enhanced device performance of AlGaN/GaN HEMTs using HfO ${ }_{2}$ high-k dielectric for surface passivation and gate oxide Semicond. Sci. Technol. 22522

[11] Kordoš P, Kúdela P, Gregušová D and Donoval D 2006 The effect of passivation on the performance of AlGaN/GaN heterostructure field-effect transistors Semicond. Sci. Technol. 211592

[12] Koehler A D et al Atomic layer epitaxy AlN for enhanced AlGaN/GaN HEMT passivation IEEE Electron Device Lett. $341115-7$

[13] Kim D et al 2007 ALD $\mathrm{Al}_{2} \mathrm{O}_{3}$ passivated MBE-grown AIGaN/GaN HEMTs on 6H-SiC Electron. Lett 43 129-30

[14] Wang H, Chung J W, Gao X, Guo S and Palacios T $2010 \mathrm{Al}_{2} \mathrm{O}_{3}$ passivated InAlN/GaN HEMTs on SiC substrate with record current density and transconductance Phys. Status Solidi C $72440-4$

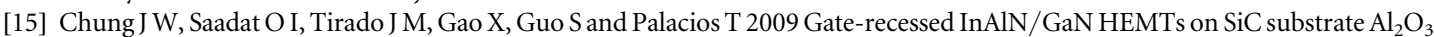
Passivation IEEE Electron Device Lett. 30 904-6

[16] Hashizume T, Nishiguchi K, Kaneki S, Kuzmik J and Yatabe Z 2018 State of the art on gate insulation and surface passivation for GaNbased power HEMTs Mater. Sci. Semicond. Process. 78 85-95

[17] Ghobadi A, Ghobadi T G U, Karadas F and Ozbay E 2018 Angstrom thick ZnO passivation layer to improve the photoelectrochemical water splitting performance of $\mathrm{TiO}_{2}$ nanowire photoanode: the role of deposition temperature Sci. Rep. 816322

[18] Li T C et al Surface passivation of nanoporous $\mathrm{TiO}_{2}$ via atomic layer deposition of $\mathrm{ZrO}_{2}$ for solid-state dye-sensitized solar cell applications J. Phys. Chem. C 113 18385-90

[19] Pascoe A R, Bourgeois L, Duffy N W, Xiang W and Cheng Y-B 2013 Surface state recombination and passivation in nanocrystalline $\mathrm{TiO}_{2}$ dye-sensitized solar cells J. Phys. Chem. C $11725118-26$

[20] Chandiran A K et al 2012 Subnanometer $\mathrm{Ga}_{2} \mathrm{O}_{3}$ tunnelling layer by atomic layer deposition to achieve $1.1 \mathrm{~V}$ open-circuit potential in dye-sensitized solar cells Nano Lett. $123941-7$

[21] Schroder D K 2006 Semiconductor Material and Device Characterization. (Hoboken, NJ, USA: Wiley)

[22] Chen Y, Ma X, Chen W, Hou B, Zhang J and Hao Y 2015 Influence of the gate edge on the reverse leakage current of AlGaN/GaN HEMTs AIP Adv. 5097154

[23] Lee D S et al 2012 Impact of $\mathrm{Al}_{2} \mathrm{O}_{3}$ Passivation Thickness in Highly Scaled GaN HEMTs IEEE Electron Device Lett. 33 976-8

[24] Stoklas R et al 2017 Influence of oxygen-plasma treatment on AlGaN/GaN metal-oxide-semiconductor heterostructure field-effect transistors with $\mathrm{HfO}_{2}$ by atomic layer deposition: leakage current and density of states reduction Semicond. Sci. Technol. 32045018

[25] Huang R et al 2018 Angular dependent XPS study of surface band bending on Ga-polar n-GaN Appl. Surf. Sci. 440 637-42 